\title{
Appropriateness of Hospital Admission for Emergency Department Patients with Bronchiolitis: Secondary Analysis
}

Gang Luo ${ }^{1}$, PhD; Michael D Johnson ${ }^{2}$, MD; Flory L Nkoy², MD, MS, MPH; Shan $\mathrm{He}^{3}$, PhD; Bryan L Stone ${ }^{2}$, MD, MS

\footnotetext{
${ }^{1}$ Department of Biomedical Informatics and Medical Education, University of Washington, Seattle, WA, United States

${ }^{2}$ Department of Pediatrics, University of Utah, Salt Lake City, UT, United States

${ }^{3}$ Homer Warner Research Center, Intermountain Healthcare, Murray, UT, United States
}

\section{Corresponding Author:}

Gang Luo, PhD

Department of Biomedical Informatics and Medical Education

University of Washington

University of Washington Medicine South Lake Union

850 Republican Street, Building C, Box 358047

Seattle, WA, 98195

United States

Phone: 12062214596

Fax: 12062212671

Email: gangluo@cs.wisc.edu

\section{Abstract}

Background: Bronchiolitis is the leading cause of hospitalization in children under 2 years of age. Each year in the United States, bronchiolitis results in 287,000 emergency department visits, $32 \%-40 \%$ of which end in hospitalization. Frequently, emergency department disposition decisions (to discharge or hospitalize) are made subjectively because of the lack of evidence and objective criteria for bronchiolitis management, leading to significant practice variation, wasted health care use, and suboptimal outcomes. At present, no operational definition of appropriate hospital admission for emergency department patients with bronchiolitis exists. Yet, such a definition is essential for assessing care quality and building a predictive model to guide and standardize disposition decisions. Our prior work provided a framework of such a definition using 2 concepts, one on safe versus unsafe discharge and another on necessary versus unnecessary hospitalization.

Objective: The goal of this study was to determine the 2 threshold values used in the 2 concepts, with 1 value per concept.

Methods: Using Intermountain Healthcare data from 2005-2014, we examined distributions of several relevant attributes of emergency department visits by children under 2 years of age for bronchiolitis. Via a data-driven approach, we determined the 2 threshold values.

Results: We completed the first operational definition of appropriate hospital admission for emergency department patients with bronchiolitis. Appropriate hospital admissions include actual admissions with exposure to major medical interventions for more than 6 hours, as well as actual emergency department discharges, followed by an emergency department return within 12 hours ending in admission for bronchiolitis. Based on the definition, $0.96 \%(221 / 23,125)$ of the emergency department discharges were deemed unsafe. Moreover, $14.36 \%$ (432/3008) of the hospital admissions from the emergency department were deemed unnecessary.

Conclusions: Our operational definition can define the prediction target for building a predictive model to guide and improve emergency department disposition decisions for bronchiolitis in the future.

(JMIR Med Inform 2018;6(4):e10498) doi: 10.2196/10498

\section{KEYWORDS}

appropriate hospital admission; bronchiolitis; emergency department; operational definition 


\section{Introduction}

Bronchiolitis is the inflammation of the bronchioles, the smallest air passages in the lungs, mainly seen in children under 2 years of age in response to viral respiratory infection. More than one-third of the children are diagnosed with bronchiolitis before 2 years of age [1]. Bronchiolitis is the leading cause of hospitalization in children under 2 years of age, and it is responsible for $16 \%$ of hospitalizations in this age group [2-5]. Each year in the United States, bronchiolitis incurs about 287,000 emergency department (ED) visits [6], 128,000 hospitalizations [2], and US $\$ 1.73$ billion of total inpatient cost (2009) [2].

Around $32 \%-40 \%$ of the ED visits for bronchiolitis end in hospitalization [7-9]. As acknowledged in the current clinical guidelines for bronchiolitis [10,11], ED disposition decisions (to discharge or hospitalize) are often made subjectively because of the lack of evidence and objective criteria for bronchiolitis management [4,12]. This causes large practice variation [3,12-23], wasted health care use, increased iatrogenic risk, and suboptimal outcomes due to unnecessary admissions and unsafe discharges [15,21,24]. About $10 \%$ of the infants with bronchiolitis experience adverse events during hospitalization [25]. At present, no operational definition of appropriate hospital admission for ED patients with bronchiolitis exists [26]. Yet, such an operational definition is essential for assessing ED care quality and building a predictive model to guide and standardize disposition decisions [26].

Our prior work [26] has provided a framework of such an operational definition using 2 concepts: one on safe versus unsafe discharge and another on necessary versus unnecessary hospitalization (Figure 1). Each concept uses a threshold value to be determined. Appropriate admissions include both necessary admissions (actual admissions that are necessary) and unsafe discharges. Appropriate ED discharges include both safe discharges and unnecessary admissions. This study aims to determine the 2 threshold values in a data-driven way, to complete the first operational definition of appropriate hospital admission for ED patients with bronchiolitis, and to report the corresponding percentages of unnecessary admissions and unsafe discharges.

Figure 1. Definition framework of appropriate admission. ?: threshold value.

$\begin{aligned} & \text { Appropriate } \\
& \text { admissions }\end{aligned}=\begin{aligned} & \text { Necessary } \\
& \text { admissions }\end{aligned}$
$\begin{aligned} & \text { Appropriate } \\
& \text { emergency } \\
& \text { department } \\
& \text { discharges }\end{aligned}$ $\begin{aligned} & \begin{array}{l}\text { Unsafe discharges: actual emergency department discharges followed by an } \\
\text { emergency department return within "?" hours ending in admission for bronchiolitis. }\end{array} \\
& \text { Safe discharges }\end{aligned}$\begin{tabular}{l}
$\begin{array}{l}\text { Unnecessary admissions: actual admissions with exposure to one or more major } \\
\text { medical interventions listed as follows for " } \leq \text { ?" hours: supplemental oxygen, } \\
\text { intravenous fluids, nasopharyngeal suctioning, cardiovascular support, invasive } \\
\text { positive pressure ventilation (mechanical ventilation), noninvasive positive pressure } \\
\text { ventilation, chest physiotherapy, inhaled therapy (bronchodilator and mucolytics), } \\
\text { and nutritional support (enteral feeding and total parenteral nutrition). }\end{array}$ \\
\hline
\end{tabular}

\section{Methods}

\section{Study Design and Ethics Approval}

In this study, we performed secondary analysis of retrospective data. The Institutional Review Boards of the University of Washington Medicine, University of Utah, and Intermountain Healthcare reviewed and approved this study and waived the need for informed consent for all patients.

\section{Patient Population}

Our patient cohort included children under 2 years of age who had ED encounters at 22 Intermountain Healthcare hospitals for bronchiolitis in 2005-2014. Intermountain Healthcare is the largest health care system in Utah, with 185 clinics and 22 hospitals providing $\sim 85 \%$ of pediatric care available in Utah [27]. We used an approach similar to that used by Flaherman et al [28-30] to identify as many ED encounters for bronchiolitis as possible.

Several International Classification of Diseases, $9^{\text {th }}$ Revision, Clinical Modification (ICD-9-CM) discharge diagnosis codes, rather than only the discharge diagnosis code of bronchiolitis, can be possibly assigned to an ED encounter for bronchiolitis. Using methods used in prior studies [28-30], we included patients with an ED or hospital ICD-9-CM primary discharge diagnosis of bronchiolitis or bronchitis (466.x), viral pneumonia (480.x), adenoviral infection (079.0), rhinovirus infection (079.3), respiratory infection due to influenza (487.0, 487.1), respiratory syncytial virus (079.6), H1N1 influenza (488.1, $488.11,488.12)$, influenza due to identified avian influenza virus $(488,488.0,488.01,488.02)$, or influenza due to novel influenza A (488.81, 488.82).

We also included all patients with any of the above as a nonprimary diagnosis, as long as the ICD-9-CM primary diagnosis was any of the following: apnea (786.03), shortness of breath (786.05), tachypnea (786.06), wheezing (786.07), other respiratory abnormalities (786.09), cough (786.2), fever (780.60, 780.61), acute nasopharyngitis (460), acute upper respiratory infections (465.x), other specified viral infection (079.89), urinary tract infection (599.0), pneumonia unspecified organism (486), unspecified viral infection (079.99), volume depletion $(276.5 \mathrm{x})$, or respiratory failure $(518.81,518.82)$.

\section{Dataset}

We extracted a clinical and administrative data set from Intermountain Healthcare's enterprise data warehouse. The data set included ED visit and hospitalization information of our patient cohort.

\section{Data Analysis}

To determine the threshold value used for defining unsafe discharges (Figure 1), we examined the length distribution of 
the interval between an ED discharge and a return ED visit within 2 weeks ending in hospitalization for bronchiolitis [31,32]. In children under 2 years of age, bronchiolitis lasting longer than 2 weeks tends to result from new infection with a differing virus strain instead of persistent infection by the same virus strain [33].

To determine the threshold value used for defining unnecessary admissions (Figure 1), we examined the patients who were hospitalized for $\leq 12$ hours and discharged with no readmission for bronchiolitis within 2 weeks. These patients tended to have been admitted unnecessarily. We used their median duration of using major medical interventions as a conservative threshold for using major medical interventions in all admissions. As shown in Figure 1, major medical interventions include supplemental oxygen, intravenous fluids, nasopharyngeal suctioning, cardiovascular support, invasive positive pressure ventilation (mechanical ventilation), noninvasive positive pressure ventilation, chest physiotherapy, inhaled therapy (bronchodilator and mucolytics), and nutritional support (enteral feeding and total parenteral nutrition) [26]. Every hospital admission with exposure to major medical interventions for no longer than the threshold was deemed unnecessary. During 2005-2012, Intermountain Healthcare iteratively modified its internal guidelines for bronchiolitis management in the ED and hospital several times, with an associated change in the distribution of the duration of using major medical interventions. After the beginning of 2013, significant changes in internal guidelines did not occur. Duration of using major medical interventions became stabilized. To compute the threshold value, we used 2013-2014 data with a stable distribution of duration of using major medical interventions. Both durations of hospitalization and using major medical interventions included only time in the hospital after the patient left the ED.

\section{Results}

Table 1 shows the demographic and clinical characteristics of our patient cohort: children under 2 years of age who had ED encounters for bronchiolitis. About $38.20 \%(14,292 / 37,417)$ of the ED visits for bronchiolitis ended in hospitalization.

Table 1. Demographic and clinical characteristics of our patient cohort.

\begin{tabular}{|c|c|c|c|}
\hline Characteristic & $\begin{array}{l}\text { Emergency department } \\
\text { visits } \\
(\mathrm{n}=37,417)\end{array}$ & $\begin{array}{l}\text { Emergency department } \\
\text { discharges } \\
(n=23,125)\end{array}$ & $\begin{array}{l}\text { Emergency department visits ending } \\
\text { in hospitalization } \\
(\mathrm{n}=14,292)\end{array}$ \\
\hline \multicolumn{4}{|l|}{ Age, n (\%) } \\
\hline$<2$ months & $4769(12.75)$ & $1646(7.12)$ & $3123(21.85)$ \\
\hline 2 to $<12$ months & $22,101(59.07)$ & $14,569(63.00)$ & $7532(52.70)$ \\
\hline 12-24 months & $10,547(28.19)$ & $6910(29.88)$ & $3637(25.45)$ \\
\hline \multicolumn{4}{|l|}{ Gender, n (\%) } \\
\hline Male & $21,536(57.56)$ & $13,399(57.94)$ & $8137(56.93)$ \\
\hline Female & $15,881(42.44)$ & $9733(42.06)$ & $6155(43.07)$ \\
\hline \multicolumn{4}{|l|}{ Race, $\mathbf{n}(\%)$} \\
\hline American Indian or Alaska native & $458(1.22)$ & $295(1.28)$ & $163(1.14)$ \\
\hline Asian & $395(1.06)$ & $222(0.96)$ & $173(1.21)$ \\
\hline Black or African American & $1017(2.72)$ & $664(2.87)$ & $353(2.47)$ \\
\hline Native Hawaiian or other Pacific islander & $2209(5.90)$ & $1243(5.38)$ & $966(6.76)$ \\
\hline White & $28,510(76.20)$ & $17,660(76.37)$ & $10,850(75.92)$ \\
\hline Unknown or not reported & $4828(12.90)$ & $3041(13.15)$ & $1787(12.50)$ \\
\hline \multicolumn{4}{|l|}{ Ethnicity, n (\%) } \\
\hline Hispanic & $9011(24.08)$ & $5975(25.84)$ & $3036(21.24)$ \\
\hline Non-Hispanic & $18,823(50.31)$ & $11,278(48.77)$ & $7545(52.79)$ \\
\hline Unknown or not reported & $9583(25.61)$ & $5872(25.39)$ & $3711(25.97)$ \\
\hline \multicolumn{4}{|l|}{ Insurance, $\mathbf{n}(\%)$} \\
\hline Private & $22,162(59.23)$ & $13,052(56.44)$ & $9110(63.74)$ \\
\hline Public & $13,448(35.94)$ & $8729(37.75)$ & $4719(33.02)$ \\
\hline Self-paid or charity & $1807(4.82)$ & $1344(5.81)$ & $463(3.24)$ \\
\hline Asthma, n (\%) & $2246(6.00)$ & $883(3.82)$ & $1363(9.54)$ \\
\hline Chronic complex condition [34], n (\%) & $2040(5.45)$ & $365(1.58)$ & $1675(11.72)$ \\
\hline
\end{tabular}


Figures 2 and 3 show cumulative length distributions in hours of the interval between an ED discharge and a return ED visit within 2 weeks ending in hospitalization for bronchiolitis. Figure 4 shows probability density function of the interval length. The probability density function was relatively large until the interval length reached the cumulative distribution curve's inflection point at about 10 to 12 hours and became smaller afterward. The cumulative distribution curve seemed to have 2 inflection points, suggesting 3 underlying distributions. As indicated by the dotted curve in Figure 4, the 3 distributions are postulated to represent an early ED return after an inappropriate ED discharge, natural disease progression in a subgroup of appropriate ED discharges, and an even later ED return due to a new viral infection after an appropriate ED discharge, respectively. When selecting the threshold value for defining unsafe discharges (Figure 1), we wanted our choice to capture the majority of unsafe discharges while avoiding contamination with ED returns not due to unsafe discharges. To help make the choice, we used the probability density function that has a local minimum at the interval length of 10 to 12 hours. We chose 12 hours, which fulfilled our selection criteria. Accordingly, $0.96 \%$ $(221 / 23,125)$ of the ED discharges were followed by an ED return within 12 hours resulting in hospital admission for bronchiolitis and were deemed unsafe ED discharges.
In 2013-2014, no major medical intervention was applied in $6.45 \%(194 / 3008)$ of the cases of hospitalization from the ED for bronchiolitis. In another $7.91 \%$ (238/3008) of the cases, 1 or more major medical interventions were applied, but the duration of using them was $\leq 6$ hours. Among the patients hospitalized in 2013-2014, 8.31\% (250/3008) were hospitalized for $\leq 12$ hours and discharged with no readmission for bronchiolitis within 2 weeks. Figure 5 shows the distribution of duration of using major medical interventions in these patients. Median duration of using major medical interventions was 6 hours, which we used as the threshold value for defining unnecessary admissions (Figure 1). Accordingly, 14.36\% (432/3008) of the hospital admissions from the ED in 2013-2014 incurred exposure to major medical interventions for no longer than this threshold and were deemed unnecessary.

By filling in the 2 threshold values in our definition framework (Figure 1) [26], we completed the first operational definition of appropriate hospital admission for ED patients with bronchiolitis. Appropriate hospital admissions include actual admissions with exposure to major medical interventions for more than 6 hours, as well as actual ED discharges followed by ED return within 12 hours ending in admission for bronchiolitis. Putting unsafe ED discharges and unnecessary admissions together, $6.08 \%$ of the ED disposition decisions for bronchiolitis were deemed inappropriate.

Figure 2. Cumulative length distribution of interval between emergency department discharge and return visit within 2 weeks ending in hospitalization for bronchiolitis.

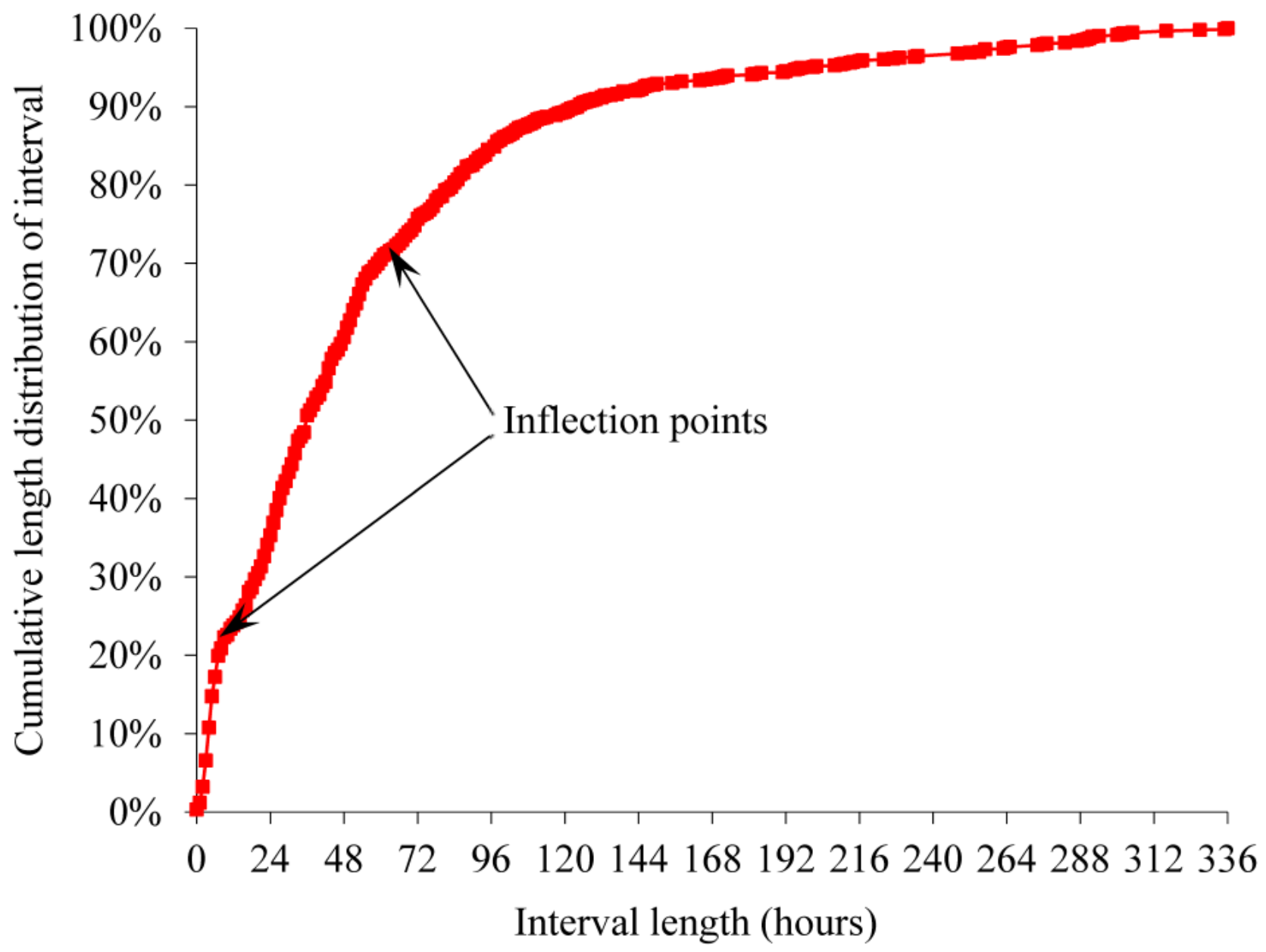


Figure 3. Cumulative length distribution of interval between emergency department discharge and return visit within 2 weeks ending in hospitalization for bronchiolitis, when the interval length is $\leq 20$ hours.

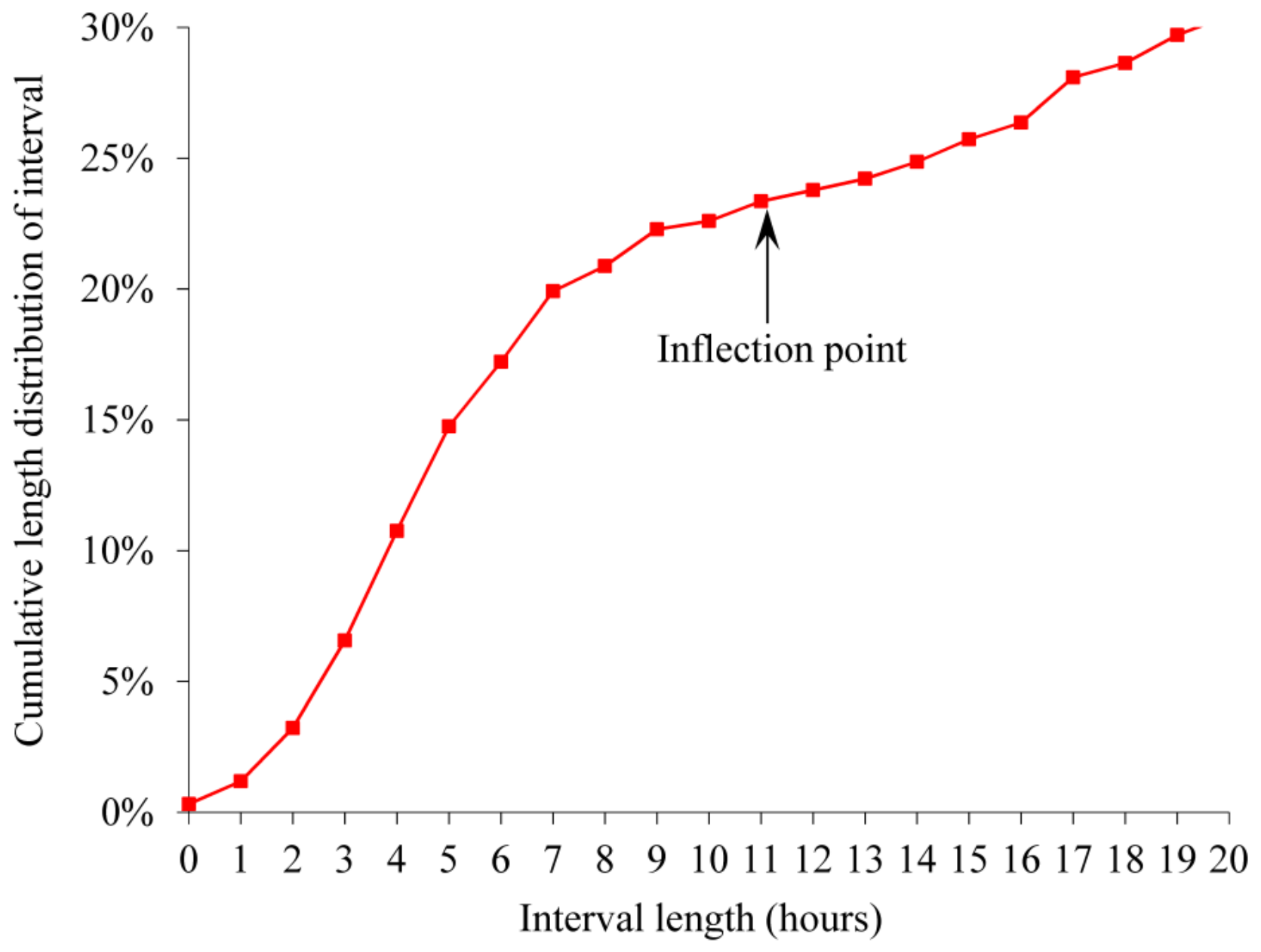


Figure 4. Probability density function of interval between emergency department discharge and return visit within 2 weeks ending in hospitalization for bronchiolitis, when the interval length is $\leq 120$ hours.

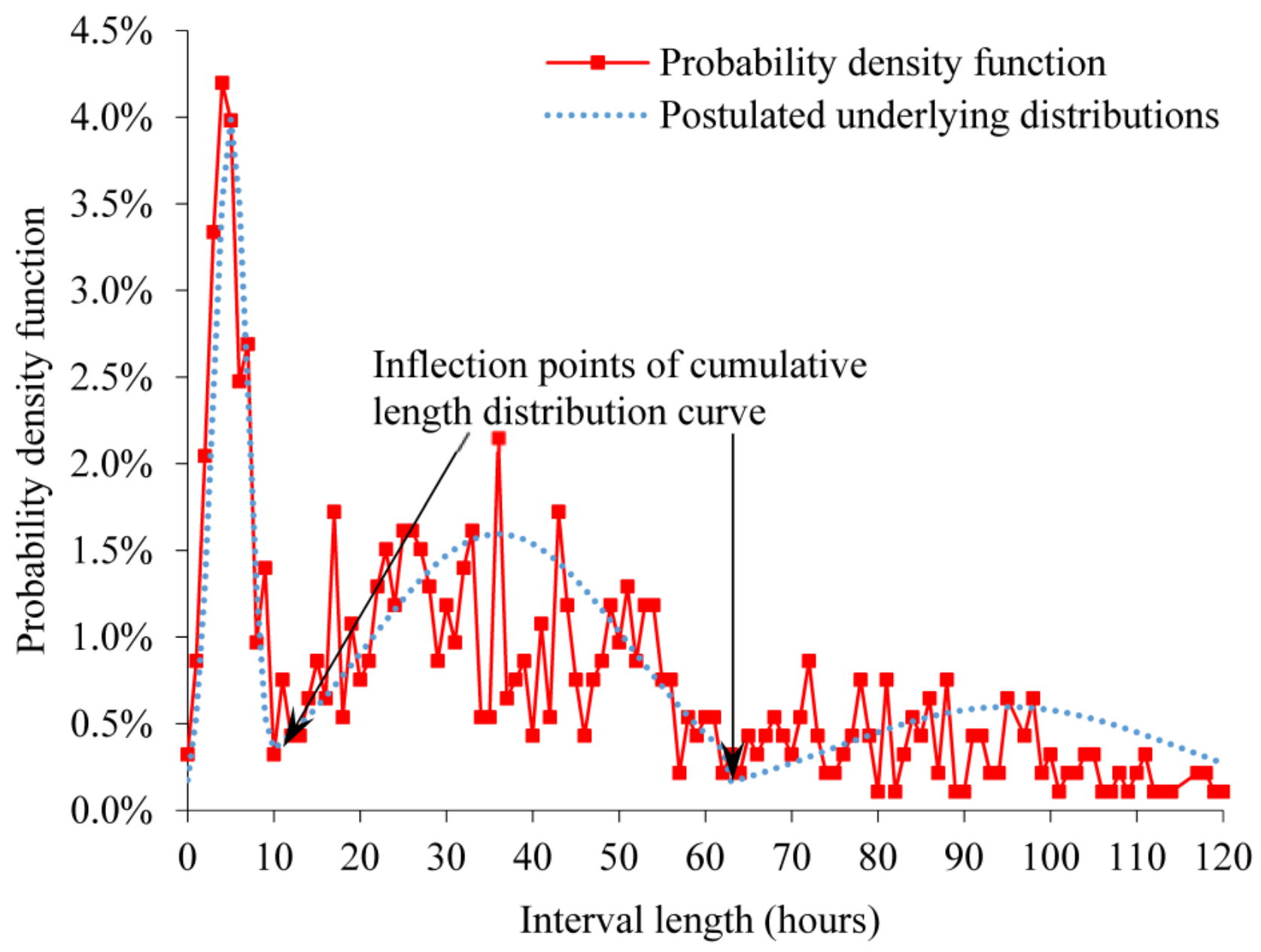


Figure 5. Distribution of duration of using major medical interventions among patients who were hospitalized for $\leq 12$ hours in $2013-2014$ and discharged with no readmission for bronchiolitis within 2 weeks.

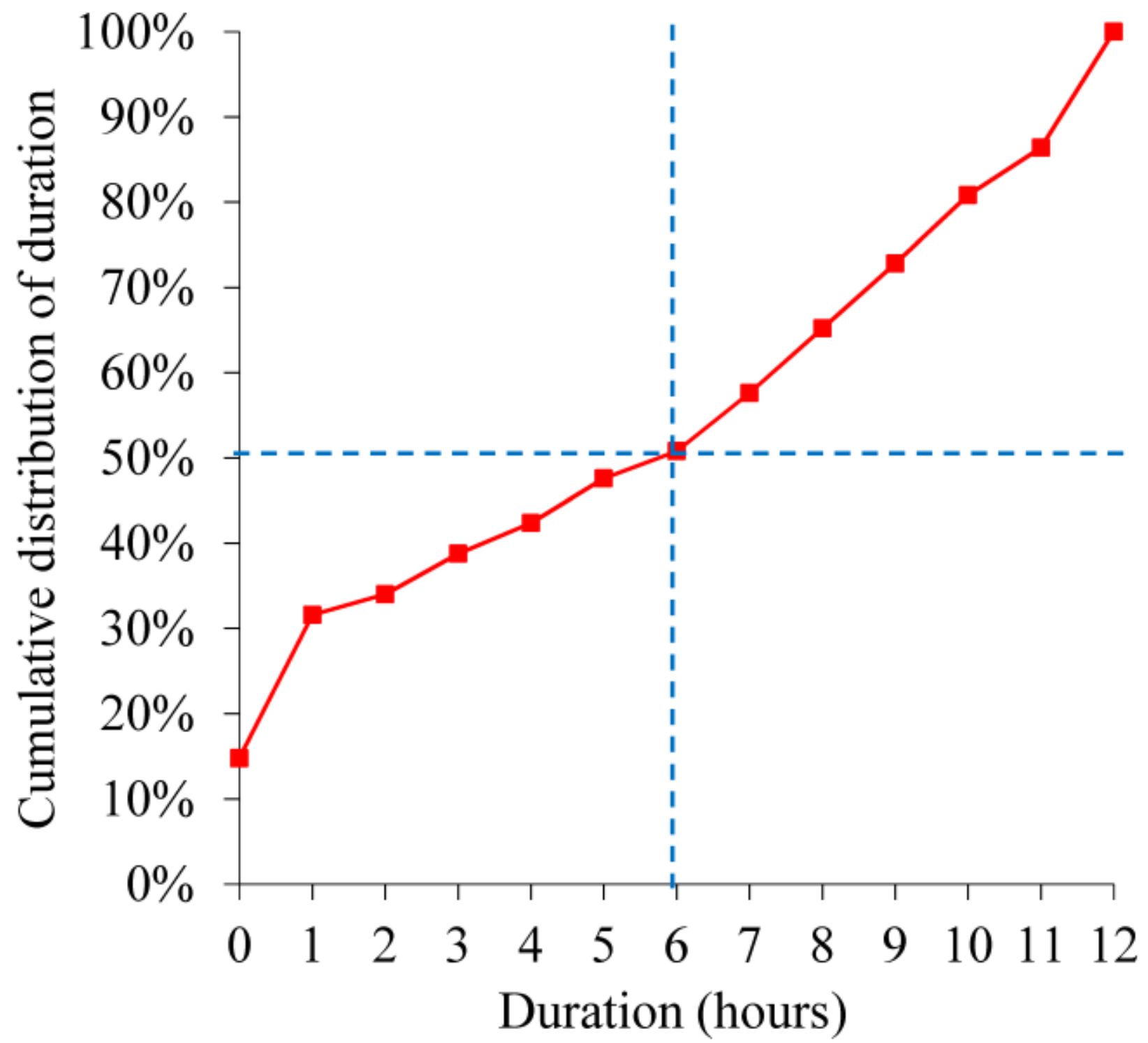

\section{Discussion}

\section{Principal Findings}

We completed the first operational definition of appropriate hospital admission for ED patients with bronchiolitis. The definition uses 2 concepts, one on safe versus unsafe discharge and another on necessary versus unnecessary hospitalization. Based on the definition, we found that many ED disposition decisions for bronchiolitis were deemed inappropriate. Our findings highlight opportunities for improving ED disposition decisions and the need to build a model to predict appropriate admission. The model could become the foundation of a decision support tool to help make appropriate ED disposition decisions for bronchiolitis, improve bronchiolitis outcomes, and cut health care costs [26]. Although the model could be built without using the ED physician's initial, tentative disposition decision as an input variable, the model would likely be more accurate if this variable is included. In either case, physicians can use the model's output to give a second thought on their initial, tentative disposition decision.

\section{Comparison With Prior Work}

Some aspects of our findings are similar to those in previous studies. In our data set, about $38.20 \%(14,292 / 37,417)$ of the ED visits for bronchiolitis ended in hospitalization. This percentage is close to the corresponding percentages (32\%-40\%) reported in the literature [7-9]. For 30 EDs in 15 US states, Norwood et al [35] have presented the length distribution of interval between an ED discharge and a return ED or clinic visit within 2 weeks for bronchiolitis. That distribution is similar to the one we have shown in Figure 2, which presents the length distribution of interval between an ED discharge and a return ED visit within 2 weeks ending in hospitalization for bronchiolitis.

Some of our findings are different from those in previous studies. In our dataset, $14.36 \%(432 / 3008)$ of the hospital admissions from the ED in 2013-2014 were deemed 
unnecessary. This percentage is smaller than the corresponding percentages (20\%-29\%) suggested in the literature [36,37]. Intermountain Healthcare has multiple collaborative partnerships among its EDs and hospitals to ensure that pediatric specialty care is co-ordinated and not focused just in a tertiary pediatric hospital. Several quality improvement projects for bronchiolitis management were completed during 2005-2012, impacting the ED and hospital care of children in multiple hospitals within Intermountain Healthcare. The average quality of ED disposition decisions for bronchiolitis made at Intermountain Healthcare could be higher than that of ED disposition decisions for bronchiolitis made at some other health care systems, particularly if those health care systems employ few pediatricians in their EDs.

\section{Limitations}

This study has several limitations. One limitation is that the study used data from a single health care system, Intermountain Healthcare, and our results may not be generalized to other health care systems. Notably, most Intermountain Healthcare hospitals are at a high elevation (more than 4000 feet above sea level). This may result in increased incidence of hypoxia. About $46 \%$ of the patients hospitalized with bronchiolitis at Intermountain Healthcare are discharged on home oxygen for outpatient management. Protocols are in place to facilitate brief hospitalizations if oxygen is the only intervention a patient needs in the hospital [30]. In the future, it would be desirable to use data from other health care systems to validate our operational definition of appropriate hospital admission for ED patients with bronchiolitis. As indicated by similarities between our findings and those in previous studies, we do not expect such validation to significantly change our results. Intermountain Healthcare is a large health care system with EDs at 22 heterogeneous hospitals spread over a large geographic area, ranging from community metropolitan and rural hospitals attended by general practitioners and family doctors with constrained pediatric resources to tertiary care children's and general hospitals in urban areas attended by subspecialists [26]. Each hospital has a different patient population, geographic location, staff composition, scope of services, and cultural background. This variation provides a realistic situation for finding factors generalizable to other hospitals across the United States.

Another limitation of this study is that Intermountain Healthcare does not have complete clinical and administrative data on all of its patients although it is an integrated health care system. Within 2 weeks of a visit to an Intermountain Healthcare ED for bronchiolitis, a patient could use a non-Intermountain Healthcare hospital for bronchiolitis again. If this occurred, our data set would miss the information on health care use that occurred at a non-Intermountain Healthcare hospital. Including data from non-Intermountain Healthcare hospitals may lead to different results. Nevertheless, we do not expect this to greatly change the accuracy of our results. Intermountain Healthcare provides $\sim 85 \%$ of the pediatric care available in Utah [27]. Thus, our dataset is reasonably, although not $100 \%$, complete in terms of capturing bronchiolitis patients' use of hospitals at Utah.

A third limitation is that this study does not consider factors, such as preference of the patient's parents, patient transportation availability, and time of day, while defining appropriate hospital admission. Many of these factors are often undocumented in patient records. For some hospital admissions from the ED that were deemed unnecessary based on our operational definition of appropriate hospital admission, the original admission decisions could be made due to these factors.

\section{Conclusions}

We provided the first operational definition of appropriate hospital admission for ED patients with bronchiolitis. Our operational definition can define the prediction target for building a predictive model in the future with the goal of standardizing and improving ED disposition decisions for bronchiolitis.

\section{Acknowledgments}

GL, BLS, MDJ, FLN, and SH were partially supported by the National Heart, Lung, and Blood Institute of the National Institutes of Health under Award Number R21HL128875. The funders had no role in study design, data collection and analysis, decision to publish, or preparation of the manuscript.

\section{Authors' Contributions}

GL was mainly responsible for the paper. GL conceptualized and designed the study, performed literature review and data analysis, and wrote the paper. BLS, MDJ, and FLN provided feedback on various medical issues, contributed to conceptualizing the presentation, and revised the paper. SH took part in retrieving the Intermountain Healthcare data set and interpreting its detected peculiarities. All authors approved the final manuscript as submitted and agree to be accountable for all aspects of the work.

\section{Conflicts of Interest}

None declared.

\section{References}

1. Zorc JJ, Hall CB. Bronchiolitis: recent evidence on diagnosis and management. Pediatrics 2010 Feb;125(2):342-349. [doi: 10.1542/peds.2009-2092] [Medline: 20100768]

2. Hasegawa K, Tsugawa Y, Brown DFM, Mansbach JM, Camargo CA. Trends in bronchiolitis hospitalizations in the United States, 2000-2009. Pediatrics 2013 Jul;132(1):28-36 [FREE Full text] [doi: 10.1542/peds.2012-3877] [Medline: 23733801] 
3. Mansbach JM, Emond JA, Camargo CA. Bronchiolitis in US emergency departments 1992 to 2000: epidemiology and practice variation. Pediatr Emerg Care 2005 Apr;21(4):242-247. [Medline: 15824683]

4. Parker MJ, Allen U, Stephens D, Lalani A, Schuh S. Predictors of major intervention in infants with bronchiolitis. Pediatr Pulmonol 2009 Apr;44(4):358-363. [doi: 10.1002/ppul.21010] [Medline: 19283838]

5. Shay DK, Holman RC, Newman RD, Liu LL, Stout JW, Anderson LJ. Bronchiolitis-associated hospitalizations among US children, 1980-1996. JAMA 1999 Oct 20;282(15):1440-1446. [Medline: 10535434]

6. Hasegawa K, Tsugawa Y, Brown DFM, Mansbach JM, Camargo CA. Temporal trends in emergency department visits for bronchiolitis in the United States, 2006 to 2010. Pediatr Infect Dis J 2014 Jan;33(1):11-18 [FREE Full text] [doi: 10.1097/INF.0b013e3182a5f324] [Medline: 23934206]

7. Marlais M, Evans J, Abrahamson E. Clinical predictors of admission in infants with acute bronchiolitis. Arch Dis Child 2011 Jul;96(7):648-652. [doi: 10.1136/adc.2010.201079] [Medline: 21339199]

8. Laham FR, Trott AA, Bennett BL, Kozinetz CA, Jewell AM, Garofalo RP, et al. LDH concentration in nasal-wash fluid as a biochemical predictor of bronchiolitis severity. Pediatrics 2010 Feb;125(2):e225-e233 [FREE Full text] [doi: 10.1542/peds.2009-0411] [Medline: 20100751]

9. Corneli HM, Zorc JJ, Holubkov R, Bregstein JS, Brown KM, Mahajan P, Bronchiolitis Study Group for the Pediatric Emergency Care Applied Research Network. Bronchiolitis: clinical characteristics associated with hospitalization and length of stay. Pediatr Emerg Care 2012 Feb;28(2):99-103. [doi: 10.1097/PEC.0b013e3182440b9b] [Medline: 22270499]

10. Scottish IGN. Bronchiolitis in children. A national clinical guideline. URL: https://www.guidelinecentral.com/summaries/ bronchiolitis-in-children-a-national-clinical-guideline/ [accessed 2015-09-21] [WebCite Cache ID 6bhQvWHzA]

11. Bronchiolitis Guideline Team, Cincinnati Children's Hospital Medical Center. Evidence-based care guideline for management of first time episode bronchiolitis in infants less than 1 year of age. URL: http://www.guideline.gov/content.aspx?id=34411 [accessed 2015-09-20] [WebCite Cache ID 6bhOyjITC]

12. Brand PL, Vaessen-Verberne AA. Differences in management of bronchiolitis between hospitals in The Netherlands. Dutch Paediatric Respiratory Society. Eur J Pediatr 2000 May;159(5):343-347. [Medline: 10834519]

13. Ducharme FM. Management of acute bronchiolitis. BMJ 2011 Apr 06;342:d1658. [Medline: 21471173]

14. Behrendt CE, Decker MD, Burch DJ, Watson PH. International variation in the management of infants hospitalized with respiratory syncytial virus. International RSV Study Group. Eur J Pediatr 1998 Mar;157(3):215-220. [Medline: 9537488]

15. Chamberlain JM, Patel KM, Pollack MM. Association of emergency department care factors with admission and discharge decisions for pediatric patients. J Pediatr 2006 Nov;149(5):644-649. [doi: 10.1016/j.jpeds.2006.05.047] [Medline: 17095336]

16. Johnson DW, Adair C, Brant R, Holmwood J, Mitchell I. Differences in admission rates of children with bronchiolitis by pediatric and general emergency departments. Pediatrics 2002 Oct;110(4):e49. [Medline: 12359822]

17. Mallory MD, Shay DK, Garrett J, Bordley WC. Bronchiolitis management preferences and the influence of pulse oximetry and respiratory rate on the decision to admit. Pediatrics 2003 Jan;111(1):e45-e51. [Medline: 12509594]

18. Plint AC, Johnson DW, Wiebe N, Bulloch B, Pusic M, Joubert G, et al. Practice variation among pediatric emergency departments in the treatment of bronchiolitis. Acad Emerg Med 2004 Apr;11(4):353-360 [FREE Full text] [Medline: 15064208]

19. Vogel AM, Lennon DR, Harding JE, Pinnock RE, Graham DA, Grimwood K, et al. Variations in bronchiolitis management between five New Zealand hospitals: can we do better? J Paediatr Child Health 2003;39(1):40-45. [Medline: 12542811]

20. Willson DF, Horn SD, Hendley JO, Smout R, Gassaway J. Effect of practice variation on resource utilization in infants hospitalized for viral lower respiratory illness. Pediatrics 2001 Oct;108(4):851-855. [Medline: 11581435]

21. Willson DF, Jiao JH, Hendley JO, Donowitz L. Invasive monitoring in infants with respiratory syncytial virus infection. J Pediatr 1996 Mar;128(3):357-362. [Medline: $\underline{\text { 8774504] }}$

22. Wang EE, Law BJ, Boucher FD, Stephens D, Robinson JL, Dobson S, et al. Pediatric Investigators Collaborative Network on Infections in Canada (PICNIC) study of admission and management variation in patients hospitalized with respiratory syncytial viral lower respiratory tract infection. J Pediatr 1996 Sep;129(3):390-395. [Medline: $\underline{8804328]}$

23. Christakis DA, Cowan CA, Garrison MM, Molteni R, Marcuse E, Zerr DM. Variation in inpatient diagnostic testing and management of bronchiolitis. Pediatrics 2005 Apr;115(4):878-884. [doi: 10.1542/peds.2004-1299] [Medline: 15805359]

24. Mansbach JM, Clark S, Christopher NC, LoVecchio F, Kunz S, Acholonu U, et al. Prospective multicenter study of bronchiolitis: predicting safe discharges from the emergency department. Pediatrics 2008 Apr;121(4):680-688. [doi: 10.1542/peds.2007-1418] [Medline: 18381531 ]

25. McBride SC, Chiang VW, Goldmann DA, Landrigan CP. Preventable adverse events in infants hospitalized with bronchiolitis. Pediatrics 2005 Sep;116(3):603-608. [doi: 10.1542/peds.2004-2387] [Medline: 16140699]

26. Luo G, Stone BL, Johnson MD, Nkoy FL. Predicting Appropriate Admission of Bronchiolitis Patients in the Emergency Department: Rationale and Methods. JMIR Res Protoc 2016 Mar 07;5(1):e41 [FREE Full text] [doi: 10.2196/resprot.5155] [Medline: 26952700]

27. Byington CL, Reynolds CC, Korgenski K, Sheng X, Valentine KJ, Nelson RE, et al. Costs and infant outcomes after implementation of a care process model for febrile infants. Pediatrics 2012 Jul;130(1):e16-e24 [FREE Full text] [doi: 10.1542/peds.2012-0127] [Medline: 22732178] 
28. Flaherman VJ, Ragins AI, Li SX, Kipnis P, Masaquel A, Escobar GJ. Frequency, duration and predictors of bronchiolitis episodes of care among infants $\geq 32$ weeks gestation in a large integrated healthcare system: a retrospective cohort study. BMC Health Serv Res 2012 Jun 08;12:144 [FREE Full text] [doi: 10.1186/1472-6963-12-144] [Medline: 22682080]

29. Mittal V, Darnell C, Walsh B, Mehta A, Badawy M, Morse R, et al. Inpatient bronchiolitis guideline implementation and resource utilization. Pediatrics 2014 Mar;133(3):e730-e737 [FREE Full text] [doi: 10.1542/peds.2013-2881] [Medline: 24534398]

30. Sandweiss DR, Mundorff MB, Hill T, Wolfe D, Greene T, Andrews S, et al. Decreasing hospital length of stay for bronchiolitis by using an observation unit and home oxygen therapy. JAMA Pediatr 2013 May;167(5):422-428. [doi: 10.1001/jamapediatrics.2013.1435] [Medline: 23479000]

31. Halfon P, Eggli Y, van Melle G, Chevalier J, Wasserfallen JB, Burnand B. Measuring potentially avoidable hospital readmissions. J Clin Epidemiol 2002 Jun;55(6):573-587. [Medline: 12063099]

32. Heggestad T, Lilleeng SE. Measuring readmissions: focus on the time factor. Int J Qual Health Care 2003 Apr;15(2):147-154. [Medline: 12705708]

33. Jartti T, Lee W, Pappas T, Evans M, Lemanske RF, Gern JE. Serial viral infections in infants with recurrent respiratory illnesses. Eur Respir J 2008 Aug;32(2):314-320 [FRE Full text] [doi: 10.1183/09031936.00161907] [Medline: 18448489]

34. Feudtner C, Feinstein JA, Zhong W, Hall M, Dai D. Pediatric complex chronic conditions classification system version 2: updated for ICD-10 and complex medical technology dependence and transplantation. BMC Pediatr 2014 Aug 08;14:199 [FREE Full text] [doi: 10.1186/1471-2431-14-199] [Medline: 25102958]

35. Norwood A, Mansbach JM, Clark S, Waseem M, Camargo CA. Prospective multicenter study of bronchiolitis: predictors of an unscheduled visit after discharge from the emergency department. Acad Emerg Med 2010 Apr;17(4):376-382 [FREE Full text] [doi: 10.1111/j.1553-2712.2010.00699.x] [Medline: 20370776]

36. Shaw KN, Bell LM, Sherman NH. Outpatient assessment of infants with bronchiolitis. Am J Dis Child 1991 Feb;145(2):151-155. [Medline: 1994678]

37. Shafik MH, Seoudi TMM, Raway TS, Al Harbash NZ, Ahmad MMA, Al Mutairi HF. Appropriateness of pediatric hospitalization in a general hospital in Kuwait. Med Princ Pract 2012;21(6):516-521 [FREE Full text] [doi: 10.1159/000339084] [Medline: 22678120]

\section{Abbreviations \\ ED: emergency department \\ ICD-9-CM: International Classification of Diseases, Ninth Revision, Clinical Modification}

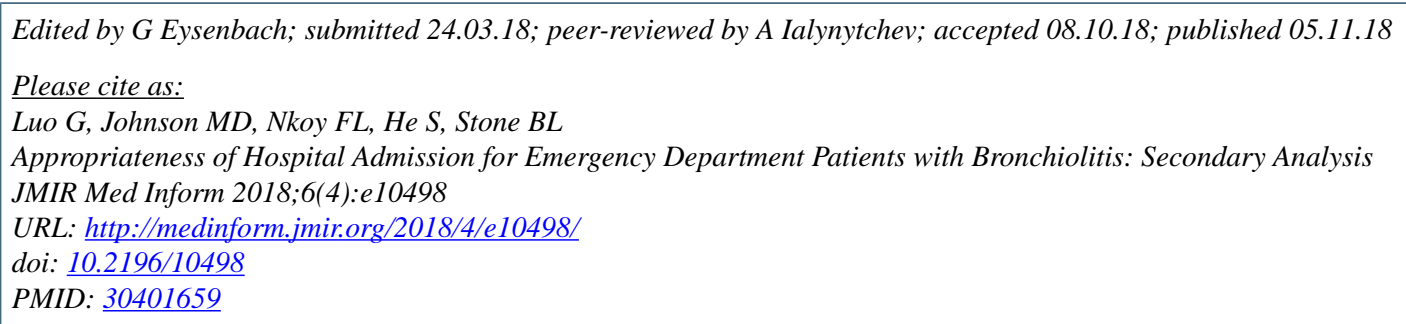

(C)Gang Luo, Michael D Johnson, Flory L Nkoy, Shan He, Bryan L Stone. Originally published in JMIR Medical Informatics (http://medinform.jmir.org), 05.11.2018. This is an open-access article distributed under the terms of the Creative Commons Attribution License (https://creativecommons.org/licenses/by/4.0/), which permits unrestricted use, distribution, and reproduction in any medium, provided the original work, first published in JMIR Medical Informatics, is properly cited. The complete bibliographic information, a link to the original publication on http://medinform.jmir.org/, as well as this copyright and license information must be included. 